\title{
GERTRUDE TENNANT, Mes souvenirs sur Hugo et Flaubert
}

\section{Ida Merello}

\section{(2) OpenEdition \\ Journals}

\section{Edizione digitale}

URL: https://journals.openedition.org/studifrancesi/45345

DOI: $10.4000 /$ studifrancesi.45345

ISSN: 2421-5856

\section{Editore}

Rosenberg \& Sellier

\section{Edizione cartacea}

Data di pubblicazione: 1 août 2021

Paginazione: 394-395

ISSN: 0039-2944

\section{Notizia bibliografica digitale}

Ida Merello, "Gertrude tennant, Mes souvenirs sur Hugo et Flaubert», Studi Francesi [Online], 194 (LXV | II) | 2021, online dal 01 septembre 2021, consultato il 15 octobre 2022. URL: http://

journals.openedition.org/studifrancesi/45345 ; DOI: https://doi.org/10.4000/studifrancesi.45345

Questo documento è stato generato automaticamente il 15 octobre 2022.

\section{(c) (i) ()}

Creative Commons - Attribuzione - Non commerciale - Non opere derivate 4.0 Internazionale - CC BYNC-ND 4.0

https://creativecommons.org/licenses/by-nc-nd/4.0/ 


\title{
GERTRUDE TENNANT, Mes souvenirs sur Hugo et Flaubert
}

\author{
Ida Merello
}

\section{NOTIZIA}

GERTRUDE TENNANT, Mes souvenirs sur Hugo et Flaubert, éd. Y. Leclerc et F. Naugrette, texte anglais traduit par F. Naugrette et D. Wargny, introduction Y. Leclerc et Postface J.-M. Hovasse, Paris, éditions de Fallois, 2020, 392 pp.

1 Gertrude TENNANT (1819-1918), esponente di punta del mondo vittoriano, animò uno dei più importanti salotti dell'epoca, al Richmond Terrace, l'imponente edificio nel cuore di Londra. Vi si potevano incontrare tra gli altri Ruskin, Wilde, Gladstone ed Henry James. Vissuta in Francia, a Parigi, per larga parte della sua giovinezza, ricevette un'educazione superiore a quella destinata al mondo femminile. Verso la fine della vita (morì di spagnola a novantanove anni) scrisse i suoi ricordi a uso familiare, per i nipoti. $\mathrm{Fu}$ proprio una nipote, nel 2005, a ritrovare in un baule di documenti il fascicolo dei souvenirs e una corrispondenza con Flaubert dal 1842 al 1881. Il volume in oggetto, uscito per Fallois, è la traduzione di manoscritti inglesi ancora inediti nella lingua originale, riuniti dai curatori in un insieme di lettere e ricordi, che si offre alla lettura con organica compattezza. Il volume è diviso in due parti: nella prima sono raccolti gli elementi che riguardano Victor Hugo: ricordi di incontri, brevi scambi epistolari, nella seconda - più ricca -, i ricordi su Gustave Flaubert, accompagnati da lettere scambiate con Gustave, Caroline e la figlia di lei, che coprono il periodo dal 1842 alla morte dello scrittore. Per la parte riguardante Hugo risulta di particolare interesse soprattutto il ricordo del soggiorno a Guernesey, con il ritratto della famiglia Hugo e di Juliette Drouet, e la descrizione dell'ambiente dello scultore Pradier, dove la Tennant ebbe l'occasione di incontrare un giorno Hugo (senza ricavarne una buona impressione). I curatori sollevano dubbi invece sulla veridicità di altri incontri e sulla visita in place des Vosges, supponendo che molti materiali siano di fantasia o frutto di un'elaborazione di testi altrui. I ricordi su Flaubert rappresentano invece una 
testimonianza di prima mano su Gustave ventenne, durante le vacanze a Trouville: sottile sotto la zazzera bionda, con calzoni blu da paesano, camicia di flanella rossa e una sciarpa annodata in vita. Insofferente delle buone maniere e delle convenienze sociali, appare dominato da una noia esistenziale molto vicina allo spleen di Baudelaire. La Tennant nota il disagio misto a disprezzo del padre nei confronti del figlio artista e sognatore, e la tristezza della madre, dominata dal lutto per i figli morti prematuramente. La scrittrice indugia su quello che sembra essere il ricordo di un flirt di giovinezza e nello stesso tempo rievoca gli ambienti e i personaggi. Il volume si mostra rilevante per la ricchezza di documentazione, l'apparato di note testuali e anche la brillante postfazione di Jean-Marc Hovasse. Qui vengono riprese le fila dell'opera, per inserire i ricordi e le lettere in un tessuto biografico dove gli incontri con i due grandi autori spiccano nella vicenda familiare di Gertrude. Non avrebbe senso - dice Hovasse ricostruire la vita di Hugo e Flaubert attraverso questi ricordi. Ma invece considerandoli per quello che sono, ossia sprazzi di luce su momenti di vita, appaiono pieni di fascino e di significato. Hovasse fa notare che i ricordi della Tennant appaiono rétro nella letteratura della Belle époque, dominata da Virginia Woolf e Proust, e suggerisce una sua similitudine col personaggio di Mme de Villeparisis. Paragone un po' troppo crudele, forse, per l'eleganza di Gertrude Tennant, che ha tenuto per cinquant'anni uno dei più importanti salotti letterari, e appare soprattutto un esempio della cultura dell'età vittoriana: si scandalizza per l'argomento di Madame Bovary e non sa capire la grandezza di Flaubert, ma conserva per lui un'attrazione (ricambiata) che durerà tutta la vita. 